\title{
IS DEFAULT RISK THE HIDDEN FACTOR IN MOMENTUM RETURNS? SOME
}

\section{EMPIRICAL RESULTS}

\author{
ISABEL ABINZANO \\ LUIS MUGA \\ RAFAEL SANTAMARIA
}

January 2013

\begin{abstract}
:
This paper analyzes the role of default risk in the momentum effect focusing on data from four developed European stock markets (France, Germany, Spain and the United Kingdom). Using a market-based measure of default risk, we show that it is not the hidden factor behind this effect. While the loser portfolio is characterized by high default risk, small size, high BTM and illiquidity, characterization of the winner portfolio is somewhat more complex. Given that the momentum strategy is the return differential between the winners and the losers, factors such as the stock market cycle or the evolution of momentum portfolios against their reference point make momentum profits difficult to forecast.
\end{abstract}

Keywords: Momentum effect, default risk, hard to value assets

JEL Code: G14, G10

\section{ACKNOWLEDGEMENTS}

This paper has received financial support from the Spanish Ministry of Science and Innovation (ECO2009-12819) and the Ministry of Economy and Competitiveness (ECO2012-35946-C02-01). Isabel Abinzano particularly acknowledges the financial support of the Andalusian Regional Government (P09-SEJ-4467).

Isabel Abinzano. Dpto. Gestion de Empresas. Universidad Publica de Navarra. Campus de Arrosadia s/n 31.006 Pamplona (SPAIN). E-mail: isabel.abinzano@unavarra.es

Luis Muga. Dpto. Gestion de Empresas. Universidad Publica de Navarra. Campus de Arrosadia s/n 31.006 Pamplona (SPAIN). E-mail: luis.muga@unavarra.es

Rafael Santamaria. (Corresponding author). Dpto. Gestion de Empresas. Universidad Publica de Navarra. Campus de Arrosadia s/n 31.006 Pamplona (SPAIN). 34948169389 E-mail: rafael@unavarra.es 


\section{Is default risk the hidden factor in momentum returns? Some empirical results}

\section{Introduction}

Medium-term return continuation, also known as "the momentum effect", has been observed in different markets and for different time periods over the last two decades. Jegadeesh and Titman $(1993,2001)$ provide evidence of this phenomenon for the US market, Rouwenhorst (1998) for several European markets, Hameed and Kusnadi (2002) for Asian markets, and Muga and Santamaría (2007a) for Latin American markets.

Despite this widespread evidence, there is an ongoing disagreement as to the source of momentum, with some scholars supporting risk-based explanations and others finding the best explanation in "Behavioral Finance" theory. Against this background, some recent studies have claimed that one of the key variables when attempting to find a satisfactory explanation for the momentum effect is default risk. Avramov et al. (2007), use US stock market data to show that momentum strategies will only achieve significant profits if constructed from low credit rating stocks, while Agarwal and Taffler (2008), using UK stock market data, conclude that the momentum effect is a direct consequence of market underreaction to distress risk. Despite approaching the issue from different perspectives, both the above studies appear to locate the source of the momentum effect in a particular type of stock characterized by high default risk. Whether or not these findings can be applied more generally, however, depends on the generalization of the default risk measures used by the authors, and the biases that they entail.

Avramov et al. (2007) use credit ratings to show that the momentum effect is significant only among low credit rating stocks. However, the default risk of a firm can vary substantially before its credit rating is up- or down-graded ${ }^{1}$. Furthermore, the fact that taking into account only credit-rated stocks biases the sample, at least with respect to firm size, and thus strongly affects the results. Note that a significant relationship between size and the momentum effect has been shown in the literature (see, for example, Hong, Lim and Stein, 2000).

Agarwal and Taffler (2008) use the Altman's Z, based exclusively on accounting data, which they categorize as a binary variable to distinguish between financially distressed and healthy firms. In addition to this simplification, the use of accounting data to estimate a firm's default risk entails serious drawbacks. This sort of information is based on past data that may tell us very little about the firm's future prospects. Moreover, since these models do not consider asset volatility, firms with the same accounting ratios would present identical levels of default risk. Furthermore, these authors use a measure that bears no

1 The use of the credit rating as a proxy for default risk implies the assumption that two stocks with the same credit rating will also have the same default risk. 
significant relationship with size or book-to-market (BTM) in their sample, despite a wealth of empirical evidence showing the link between the momentum effect and these two stock characteristics ${ }^{2}$.

To create a wider framework of analysis, this paper approaches the relationship between momentum and default risk in four key European stock markets: France, Germany, Spain and the $\mathrm{UK}^{3}$.

In this context, we begin with a preliminary analysis using the credit rating data for the four stock markets of interest to this study. Our results differ from those obtained by Avramov et al. (2007) and create more than reasonable doubt that their findings can be generalized beyond the US market. The sample characteristics of credit-rated firms differ across European markets and this too may have had a noticeable effect on findings. Indeed, the percentage of firms with a BB rating, which Avramov et al. (2007) use as the reference for a low credit rating, is $12.99 \%$ in their sample for the US, versus $11.2 \%$ for Germany, $10.84 \%$ for the UK, $10.52 \%$ for Spain and only $7.54 \%$ for France.

Secondly, for a deeper analysis of the relationship between default risk and momentum, following Vassalou and Xing (2004) we propose the use of a market-based measure of default risk based on the Black-Scholes-Merton (BSM) option-pricing model, where a firm's default risk measure is derived from the market prices of its shares. This method overcomes some of the problems associated with the default-risk measures used in the studies cited above.

The results obtained show that, for all the markets analyzed, high default risk is a characteristic of the loser portfolios, but not of the winner portfolios, which exhibit low-tomedium levels. This implies that default risk is not necessarily a characteristic of momentum strategies. Finally, by using default-risk-neutral portfolios conditioned on different variables associated with the momentum effect, we show that default risk is not the key factor in explaining momentum.

This study thus makes several contributions to the literature. Firstly, we test whether, as suggested by studies such as Avramov et al. (2007) or Agarwal and Taffler (2008), the momentum effect is exclusive to firms that are insolvent or have a low credit rating. To do this, we use data on four European markets with different market-clearing mechanisms and stock characteristics (size, BTM, liquidity, etc.), that also form part of two very different financial systems: the Anglo-Saxon and the Continental system. These sample characteristics add robustness to the findings and make them less dependent on countryspecific characteristics. Secondly, as a proxy for default risk, we use the BSM measure, which imposes hardly any sample restrictions and allows for the efficient incorporation of

\footnotetext{
${ }^{2}$ References to size have appeared in studies from Hong, Lim and Stein (2000) to more recent works, in which size is associated with information uncertainty (see Jiang et al., 2005 or Zhang, 2006) and may help to explain the momentum effect, while references to BTM began to appear as early as Daniel and Titman (1997).

3 The similarity of the findings for all four of the markets considered strongly supports their robustness to different clearing mechanisms, stock characteristics, financial systems (Anglo-Saxon versus Continental), cultural dimensions, corporate governance patterns and legal system quality.
} 
future stock expectations. Thirdly, we use non-parametric techniques (neutral strategies) to test whether the momentum effect is a response to significant default-risk exposure, by using momentum-linked conditioning variables. Fourthly, we run a robustness test by incorporating liquidity as an additional variable in a more recent period. Finally, we discuss the source of momentum strategy profits.

The study is organized into eight sections. Section 2 presents the database and the BSM measure, which is used in this study as a proxy for default risk. Section 3 analyzes momentum profits in the four markets considered, and the variables characterizing each of them. Section 4 analyzes the outcome of using the credit rating as a proxy for default risk in European markets. Section 5 presents the results of the analysis of the relationship between default risk and momentum when using the BSM measure, and the results following the implementation of various default-risk-neutral strategies. Section 6 presents a brief analysis of the robustness of the results to the introduction of a liquidity proxy into the analysis. Section 7 discusses the source of momentum strategy profits and the study ends with section 8 , where we present the main conclusions.

\section{Database and default-risk measure}

\subsection{The database}

The data, taken from the Thomson Financial database, refer to all stock listed in four of the key European markets: France, Germany, Spain, and the United Kingdom between January 1992 and January 2007. For France, we use all firms listed on Datastream; for Germany, those listed on Xetra or on the Frankfurt stock Exchange, selecting the data from the Frankfurt stock Exchange for firms listed on both. For Spain, we used all firms listed on the continuous market and, finally, for the UK, we used all firms listed on the London Stock Exchange SETS (Electronic Trading Service). In line with Ince and Porter (2006), we have screened and corrected the database. We have removed padded zero-return records at the end of delisted firms, we have removed all nonlocal firms and all listing other than those on the primary exchange and all listing with Type not equal to Equity. We include only those firms that checked YES in the "Primary quote" field. Stock priced below 1.0 Euros (or Pounds Sterling in the case of the UK) were also removed.

Bank, finance companies and insurance companies were excluded from the analysis, because the peculiarities of their capital structure might skew the desired default risk data. Although the removal of firms from the finance sector introduces a sample bias, it does not matter for the proposed analysis due to the specific characteristics of this type of company. Indeed Muga and Santamaría (2007b) show that momentum returns on finance sector stocks are not statistically significant. 
Finally, the availability of data needed to calculate the BSM measure also had a noticeable impact on the sample, particularly during the first years of the study period. Nevertheless it is important to emphasize that our sample size is on average 19 times greater than the sample with the information of credit rating for the French Stock Market, 15 times greater for the UK stock market and, 11 and 9 times for the German and Spanish markets, respectively. So it offers a better way to analyze the relationship between default risk and momentum in Europe. The average, maximum and minimum number of stocks available for the study sample and for the different markets considered in the study are given in Table 1, which also shows the average values of the different variables used in the analysis (return, BTM, size and BSM).

Given the nature of the study, we use monthly data for the different variables. Following Vassalou and Xing (2004), we avoid problems related to reporting delays by using debt data for the last three quarters of the current year and the first quarter of the past year. In line with other studies ${ }^{4}$, we calculate the book value of debt as the sum of shortterm debt and $50 \%$ of long-term debt.

To obtain a homogeneous risk-free interest rate for the whole of the study period and the four markets considered, our reference was the Maastricht Criterion Bond Yield (MCBY), published by EUROSTAT and based on the return rate for the ten-year bond secondary market.

\subsection{Measuring default risk}

As a proxy for default risk we use the BSM measure instead of using credit rating or the accounting-based measures. As we have already mentioned, the use of the credit rating as a proxy for default risk has the disadvantage of that there is no available credit rating for some stocks, especially small firms, and that this could result in a size-biased sample, when empirical evidence has shown a significant relationship between momentum and firm size. For this reason, the sample of credit rated firms could not be adequate to test the relationship between momentum and default risk. Furthermore, it has also other disadvantages. One of them is that a firm's credit worthiness can vary substantially before its credit rating is readjusted. Another is that it implies that two firms with the same credit rating will also have the same default risk. However, as shown by Crosbie and Bohn (2003), substantial differences in default rates may exist within the same bond rating class.

The use of accounting-based measures has also its disadvantages. For one thing, account statements are intended to measure past performance and may not tell us very much about a firm's future prospects. For another, firms prepare accounting statements under the going concern principle, which assumes that the firm will not go bankrupt. Another major drawback of these measures is their failure to consider asset volatility,

\footnotetext{
${ }^{4}$ See, for example, Crouhy et al. (2000), Crosbie and Bohn (2003) and Vassalou and Xing (2004).
} 
which leads them to conclude that firms with similar ratios will have exactly the same likelihood of going bankrupt. However, volatility is a crucial variable when attempting to predict default risk because it captures the probability of a firm's assets being insufficient to cover its liabilities. Ceteris paribus, the higher the volatility of a firm's asset value, the greater its default risk.

An alternative to using the above-mentioned measures of default risk is to construct a measure using firms' market share prices, as in Moody's KMV model, Vassalou and Xing (2004), Byström et al. (2005) and Byström (2006), among others. These studies start from Merton's (1974) proposal, which is to consider the firm's own equity value as a European call option on its assets value and use the Black and Scholes (1973) formula to calculate the value.

As explained in Appendix I, the measure proposed in this paper for the approximation of default risk is given by the following expression 5 :

$$
P_{d e f, t}=N\left(-\frac{\ln \frac{V_{A, t}}{D_{t}}+\left(\mu_{t}-\frac{\sigma_{A, t}^{2}}{2}\right)(T-t)}{\sigma_{A, t} \sqrt{T-t}}\right)
$$

where $V_{A, t}$ is the value of the firm's assets at time $t, \mu_{t}$ is the expected immediate rate of return on $V_{A, t}, \sigma_{A, t}$ is asset return volatility, $D_{t}$ is the debt's face value, $T$ is the maturity period and $N(\cdot)$ is the cumulative probability of the Normal distribution.

To find the values of $V_{A, t}$ and $\sigma_{A, t}$ we use an iterative process starting from the market price of the firm's shares. Thus, the advantage of the BSM measure over accounting based models is that it not only considers past data, but, by using the market price of the shares, it also incorporates investors' expectations regarding their future performance. It also takes into account asset return volatility. Hillegeist et al. (2004) compare it in this respect with Altman's (1968) Z (1968) and Ohlson's O-Score (1980), finding that the BSM measure provides significantly more information about the firm's default risk than either of the others, which is why they recommend the use of the BSM measure instead of traditional accounting-based measures as a default probability proxy.

Furthermore, compared with the credit rating, as a default proxy, the BSM measure has the advantage of no lag between variation in credit worthiness and its incorporation into the risk measure, given that in the BSM measure market prices are discounting expected future cash flows. In addition, it is a firm-specific measure in that it provides a

\footnotetext{
${ }_{5}^{5}$ As we use the default proxy only for sorting purpose, we compute probability of default, instead of the distance to default measure as in Vassalou and Xing (2004).
} 
value for each firm based on its financial situation and its capitalization, which may differ from that obtained for another firm with the same credit rating, thus enabling more finely tuned rankings. Finally, requiring only a minimum amount of information, it provides a measurement value for every firm, not just those that are credit-rated.

\section{The momentum effect. Results and portfolio characteristics}

As a first step, we present the results of various momentum strategies implemented in the individual markets considered and the full sample of stocks from all four markets, using the calendar time approach proposed by Jegadeesh and Titman (1993) which avoids the auto-correlation problems present in event-time strategies. The actual procedure for this study was as follows. At a certain point in the sample period, the stocks are ranked by their cumulative returns over the previous $\mathrm{J}$ months (formation period) ${ }^{6}$ and classified by quintiles, where the stocks in the top-performing quintile are assigned to the winner portfolio and those in the bottom quintile to the loser portfolio. The "momentum strategy" consists of taking a long position on the winner portfolio and going short on the losers. These portfolios are held on for a horizon of $\mathrm{K}$ months following their formation (the holding period). Thus, different momentum strategies can be constructed from different combinations of formation and holding periods, which, for the purposes of this study, were $\mathrm{J}=6$ and $\mathrm{K}=3,6,9$ and 12 .

The results of the various strategies for the four markets are given in Table 2, where it can be seen that the momentum effect is positive and significant across all strategies and all four markets. The strategy returns range between a monthly average of $2.64 \%$ for $\mathrm{J}=6$ $\mathrm{K}=3$ in the UK stock market and $0.42 \%$ for $\mathrm{J}=6$ and $\mathrm{K}=12$ in the Spanish stock market, where the returns were significant only at the $10 \%$ level. This enables us to conclude that the momentum effect is present in all four of the stock samples considered. The momentum profits in some markets come from long positions in the winner portfolio and in others from short positions in the loser portfolio, with no observable pattern across markets.

Given this return differential between the winner and loser portfolios in the different stock markets, and prior evidence about the stock characteristics, Table 3 shows the characteristics of the portfolios in terms of size, BTM and default risk computed with the BSM measure, for the $\mathrm{J}=6$ formation period return quintiles. As can be seen, the first quintile portfolio (losers) shows the highest default risk, the highest BTM ratio and smallest firm size across all markets. However, these characteristics do not present an overall monotonic pattern across the different quintiles. Focusing on the default risk characteristic for the UK, French and Spanish markets and the sample as a whole, we can

\footnotetext{
${ }^{6}$ Jegadeesh and Titman (1993) use deciles to construct momentum strategies. In their paper, both the formation period, J, and the holding period, $\mathrm{K}$, take values of: $3,6,9$ and 12 , making a possible total of 16 different momentum strategies.
} 
see how default risk falls gradually as we move across from the loser portfolio towards the winner portfolio which shows an increase that is not great enough to put it into second place in the default risk ranking except in the Spanish stock market. No such momentary peak in default risk pattern appears in the loser portfolio for the German stock market.

Size shows a similar pattern across portfolios for all four markets. As already mentioned, average firm size is lowest in the loser portfolio, increasing monotonically towards the winner portfolio, where it drops slightly, although in no case to the level of the loser portfolio.

Finally, the BTM ratio also presents a similar pattern across all four markets, the loser portfolio showing the lowest average values and the winner portfolio the highest.

These results show that, despite some regularity in the pattern of stock characteristics across the momentum strategy portfolios, they are most pronounced in the loser portfolio (on the short side of the transaction), which contains smaller stocks with higher default risk and BTM ratios.

\section{Momentum and credit rating}

Firstly, in order to validate the findings of Avramov et al. (2007), we have used Moody's credit rating data accessed through FACSET for the different European stock markets considered. To homogenize the sample for the purposes of this analysis, the return data were taken from the same database. A preliminary analysis was run to check for the presence of the momentum effect in both credit-rated and non-credit-rated stocks in the available sample ${ }^{7}$.

The results for the $\mathrm{J}=6, \mathrm{~K}=6$ strategy are given in Table $4^{8}$. Screening for momentum across the entire database reveals significant positive returns in all four markets and the full sample, with average monthly returns ranging between 1.81\% (Germany) and 0.91\% (France). However, these results are lower overall than those obtained for the entire DataStream database.

Having verified the presence of momentum using the selected database, it is worth checking Avramov et al.'s (2007) reported finding that this effect is concentrated mainly in firms with a low credit rating. To this end, we constructed momentum strategies in all four markets initially for credit-rated firms. The results for the full sample of credit-rated firms across all four countries reveal no evidence of significant momentum. What is more, the momentum strategy constructed from credit-rated stock in the German and Spanish stock markets yields negative, although not significant, returns, as can be seen from Table 4.

\footnotetext{
${ }^{7}$ It should be noted that the FactSet database lists far fewer stocks than Datastream and is also subject to survivorship bias and probably also to stock size bias, which could skew the results. The average number of firms by country (including financial institutions) is 85 firms for Spain, 500 for France, 503 for Germany, and 439 for the UK.

${ }^{8}$ Due to the small number of credit-rated firms in the European stock markets, which gave a sample average of 72 , the momentum strategies in this section were constructed by sorting the stocks into past return tertiles.
} 
Finally, the stocks of the various markets were sorted into high and low credit-ratings by dividing their rating by the median, and then used to construct a new momentum strategy using the procedure described above. Although the low credit-rating stocks in the full sample and the UK, Spanish, and French stock markets show higher momentum, in no case do they show significant returns, as can be verified from the data displayed in Table 4. These results differ from those reported by Avramov et al. (2007) where low credit ratings were associated with significant momentum profits. These results might be due to biases related to credit rating coverage, namely, firm size and solvency. In Europe, when firms are credit rated it is usually because they have needed a credit rating in order to gain access to international finance markets. They therefore tend to be larger and more solvent than the average credit-rated firm in the US, where there is a greater degree of coverage. In fact, in Germany, credit-rated firms are 14.24 times bigger on average than firms in general ${ }^{9}$. In France they are 10.71 times bigger. In the UK they are 5.96 times bigger and in Spain 3.61 times bigger, whereas in the database of US firms used by Avramov et al. (2007) the ratio is only 3.12. Furthermore, as already noted, in Avramov et al. (2007) 13\% of the firms had a low credit rating, versus an average of $10 \%$ in the countries analyzed in this study. Both these issues may affect the results. Indeed, the literature has shown a clear relationship between size and momentum.

Despite these considerations, the results leave no doubt as to the fact that in Europe the momentum effect is not present (much less exclusively) among low credit rating stocks ${ }^{10}$. In the US stock market at least, a low credit rating might be a good proxy for firms with high information uncertainty, (to use the terminology employed by Jiang et al., 2005 or Zhang, 2006), stocks that are hard to value or to arbitrage (Baker and Wurgler, 2006), or stocks attracting limited attention (Abody et al., 2010), characteristics, which, as already noted, might be behind the origin of the momentum effect. However, credit rating does not exhibit the same properties when the analysis switches to European markets.

\section{Momentum and default risk}

In this section, we use the BSM measure as a proxy for default risk to test whether there is momentum effect only in the sample of stocks with high default risk. As already noted, this measure imposes very few restrictions, except the need to exclude stock from the financial sector because of its peculiar capital structure. However, since these stocks tend to have above-average credit ratings and to qualify for the medium-to-large cap categories,

\footnotetext{
9 The size bias is considerably higher in the credit-rated firm sample than in our BSM sample. In Germany average firm size of BSM sample is 2.64 times bigger than the German overall database, 2.43 times bigger in Spain, 1.57 in France and 1.41 in UK.

${ }^{10}$ It is important to emphasize that in the European stock markets analyzed there are few companies which have non-investment grade issuer ratings and it is not possible to compute the momentum portfolios only using these firms. As a consequence, the results obtained are not totally incompatible with those offered by Avramov et al. (2007).
} 
their removal does not deprive the study sample of suitable stocks for the formation of momentum strategies ${ }^{11}$.

The resulting BSM data are then used to sort the stocks into quartiles (the Spanish stocks into tertiles) and the results from $\mathrm{J}=6 \mathrm{~K}=6$ momentum strategies are calculated for the quartiles of each country (tertile in the case of Spain) and for the full sample. If default risk is the key variable, the momentum profits should be concentrated in the higher default risk groups and those with lower risk levels should report no significant returns.

As can be seen from Table 5, these predictions are fulfilled only in the Spanish stock market, where the only group of stocks showing significant momentum is the high default risk group. However, the highest returns in the full sample, and the UK and French markets appear in the two middle default risk quartiles, while in Germany the highest returns appear in the lowest, although significant momentum profits are found in all three of these markets. These findings contradict the evidence put forward by Avramov et al. (2007) and Aggarwal and Taffler (2008). Therefore, we cannot conclude, overall, that the momentum effect is present only in high default risk firms.

This evidence might be explained by the relationships between the BSM measure and the variables used to approximate ambiguity about asset values. In fact, momentum is stronger in stocks that have high information uncertainty, thus raising an essential question, which is whether the effect of default risk on momentum profitability is subsumed by information uncertainty. To address this question, we assess the robustness of momentum returns across the default risk dimension based on $3 \times 3$ portfolios sorted independently on default risk and variables that proxy for information uncertainty (size and BTM). ${ }^{12}$

The results (see Table 6) point to a stronger relationship between momentum and default risk in certain markets, but still fail to confirm the prediction that higher momentum profits will be found in stocks with higher BSM values (higher default risk), allowing us to predict such risk is not the key variable behind the momentum effect.

Focusing on the relationship with size, momentum profits in the UK stock market are significant for all the groups considered, with an overall pattern of higher returns in higher versus lower default risk groups. However, the portfolio showing the highest momentum effect is still one with a medium level of default risk, where the average monthly return is 2.97\%. In the German stock market, the negative relationship with no conditioning variable appears to be concentrated mainly among small stocks, where those with a low level of default risk show significant momentum. The remaining size-sorted groups show no sign of this relationship and the medium size/high default risk portfolio yields the highest momentum profits. In the French stock market also, the relationship between default risk

\footnotetext{
${ }^{11}$ Indeed, as already noted, Muga and Santamaría (2007b) show that in the financial sector momentum strategies do not yield significant returns.

${ }^{12}$ For the sake of diversification, the momentum strategies in this study are formed based on past return tertiles.
} 
and momentum breaks down in the small size group, where there is no significant momentum in high default risk stocks. In the other two size-sorted groups, however, the returns are higher in high versus low default risk stocks, with greater momentum appearing in the medium size/high default risk strategy where the average monthly return is $1.47 \%$. In the Spanish stock market, the returns are always higher in high than in low default risk stocks of the same size, although the strategy produces significant returns only in small firms. Finally, both in the full and UK samples, significant returns are found for all the momentum strategies, with the highest average returns being associated with high default-risk and average firm size.

These results reveal that the inclusion of small firms, which are excluded from Avramov et al. (2007), can alter the relationship between the momentum effect and default risk, as shown by the results for the French and German markets and, even more clearly, by those of the Spanish stock market.

The conclusions regarding the relationship between default risk and the momentum effect still hold for the results conditioned on the BTM variable. Thus, in the UK market all the strategies are significant, with medium level default risk groups showing higher returns. In the Spanish stock market, higher returns are obtained in high versus low default risk groups with similar BTM ratios. In the French stock market, the relationship with default risk is as expected in the low and medium BTM groups, while the strategy returns for the high BTM groups lack significance. No clear relationship can be detected in the BTM-conditioned results for Germany. Across the sample as a whole, higher returns from the momentum strategy are found in high default-risk stocks within the mid-to-high book-to-market bracket, with all the strategies proving significant.

This same table shows that the returns to the momentum strategies implemented in the various markets and the full sample are higher in the lower BTM groups, irrespective of the distress risk level, giving further evidential support to the argument that default risk is not the key variable for explaining or characterizing momentum strategies. However, this possibility cannot be completely discarded on the strength of the existing evidence. This induced us to analyze strategies that are "neutral" for certain variables using the following procedure. The stocks are first sorted into groups based on their values in one of the characteristics. The winner and loser stocks in each group are then used to form winner and loser portfolios for each time interval, thus creating a new "momentum strategy" in which the winner and loser portfolios will be diversified by that variable. The variable or characteristic is considered to be determinant if the new portfolios perform in a significantly different way from the original one (see, for example, Rouwenhorst 1998 or Hameed and Kusnadi, 2002 for further details).

Neutral strategies provide a more general non-parametric option than risk factorspecific models (as used by Agarwal and Taffler, 2008) or samples excluding firm 
observations with low credit rating (as in Avramov et al., 2007), which may exclude other relevant explanatory factors.

The results of the default risk neutral strategies (see Table 7) still show significant returns for the $J=6 \mathrm{~K}=6$ strategy in all four of the markets analyzed. In fact, the strategies have very similar average values to those yielded by the ordinary momentum strategies. Table 7 also includes the results of the default risk-neutral strategies conditioned on size and BTM. The returns are still similar to those yielded by the neutral and ordinary strategies, revealing that default risk does not appear to be the key to explaining the momentum effect. In other words, these results enable us to conclude that default risk exposure is not the hidden factor behind the momentum effect.

\section{Testing for robustness}

This section incorporates liquidity as an additional conditioning variable in the relationship between momentum and default risk. This variable has a two-way causal relationship with default risk (Vassalou et al., 2005) and the potential to predict future return performance because, among stocks with high default risk, higher returns should be expected from those with higher versus lower levels of illiquidity exposure.

In this study, liquidity is approximated by the illiquidity measure developed by Amihud (2002), which is the average ratio of the absolute daily return to the (monetary unit) trading volume on that day:

$$
I L_{i, t}=\frac{1}{D_{t}} \sum_{d=1}^{D_{t}} \frac{\left|R_{i, t}\right|}{V_{i, t}}
$$

where $D_{i, t}$ is the number of days for which data are available for stock $i$ in month $t$, and $R_{i, t}$ and $V_{i, t}$ denote the daily return and the daily trading volume (in monetary units), respectively, at day $t$.

Since very little primary data for the nineteen nineties are available from Datastream (Thomson Financial) for the calculation of this measure, our calculation covers the period from the year 1999 (2000 for Germany) onwards, when there began a gradual increase in the number of stocks for which daily trading volume data were available.

This forward shift in the sampling period provided the opportunity to test the robustness of the findings to the sample period analyzed, since the momentum effect could be related to stock market cycles (Cooper et al., 2004 and Muga and Santamaria, 2009).

The characteristics of the momentum portfolios show hardly any variation ${ }^{13}$. Again, the losers are small stocks with the highest default risk and BTM ratios (except for Spain where they have the second highest). The profile of the winners, with their average risk and size values, is less clear-cut. The only characteristic common to all the markets analyzed is

\footnotetext{
13 The results are available from the authors upon request.
} 
a lower BTM ratio. The data for illiquidity of the momentum portfolios shown in Table 8 are quite illustrative. Except in the full sample and in the French stocks market, the loser portfolio is made up of stocks showing the highest illiquidity and the winner portfolio of those showing the highest liquidity. These relationships with the momentum portfolios are fairly similar to those displayed by the default risk and size.

The results for the overall period hold for risk-sorted portfolios. In Spain, the greatest momentum appears among stocks with high default risk, but in France and the UK it appears among medium-risk stocks and in Germany among the low-risk. The inclusion of size and BTM as conditioning variables has barely any impact on the above findings.

The incorporation of illiquidity into the portfolio decision-making process provides some additional data emphasizing the multivariate role of the momentum effect (see Table 9). In Spain, the highest momentum no longer appears in association with the highest default risk levels once liquidity enters into the equation, since the highest momentum appears among illiquid stocks with low distress risk. In France, momentum profitability is highest among stocks with a medium-to-high level of distress risk and medium liquidity. In Germany, the highest profits come from medium-to-low default risk stocks, almost irrespective of their illiquidity level. Furthermore, at high distress risk levels, significantly positive returns are found only among the most liquid stocks. Although the results for the UK and the full sample are closer to expectations, with higher returns in the high default risk / high illiquidity groups, this is not where the highest momentum values are found. In addition, the momentum effect in low default risk stocks is found in association with high or medium liquidity but not with illiquidity.

Finally, it should be noted that the risk-neutral strategies, when conditioned on liquidity, yield significant returns, in no way different from the risk-neutral strategies without conditioning on any other variable or the ordinary strategies for the period 1999 to 2007. Specifically, $0.65 \%$ for Spain, $2.31 \%$ for the UK, $1.41 \%$ for France and $2.07 \%$ for Germany, all significant at the 5\% level according to the Newey-West corrected t statistic, thus confirming the preceding section's finding that exposure to default risk does not provide the explanation for the momentum effect.

\section{Where do momentum strategy profits come from?}

The findings of this study for the four European stock markets considered lead us to relativize the findings of Avramov et al. (2007) or Aggarwal and Taffler (2008) regarding the relationship between default risk and momentum profits. According to our results, high default risk is a characteristic of the loser portfolio, which also features other characteristics, such as small size, high BTM and illiquidity. Both default risk and these other stock characteristics have been used in the literature to identify stocks affected by information uncertainty (Jiang et al., 2005 or Zhang, 2006), stocks that are hard to value or 
to arbitrage (Baker and Wurgler, 2006) and stocks receiving limited attention (Abody et al., 2010). Note also that stocks presenting these characteristics are more vulnerable to investors' behavioral biases. In fact, some behavioral finance models, such as those developed by Kent, Hirshleifer and Subrahmanyam (1998, 2001) and Hirshleifer (2001) have shown that investors' behavioral biases are stronger among relatively hard-to-value stocks operating in informationally-sparse environments. More recently, Kumar (2009) has shown empirically that investors exhibit stronger behavioral biases, such as the disposition effect, overconfidence, familiarity, representativeness, and limited attention, when stocks are more difficult to value and when market-level uncertainty is higher. Various studies (Cooper et al., 2004, Grimblatt and Han, 2005, or Muga and Santamaría, 2009) have cited one or other of these behavioral biases to explain the momentum effect. The latter types of stock attract the attention of investors with behavioral biases, thus driving momentum profits (Muga and Santamaría, 2007b).

Antoniou et al. (2012) assert that investor sentiment affects the profitability of momentum strategies. They argue that investor sentiment causes cognitive dissonance, thereby slowing down information diffusion. This, together with short selling constraints, impedes the arbitrage trading of loser stocks, thus strengthening momentum during optimistic periods. As a complementary analysis, we are going to examine the explanatory capacity of investor sentiment in $\mathrm{J}=6, \mathrm{~K}=6$ momentum strategies, and in momentum portfolios constructed entirely from low (high) default-risk stocks. We construct the FamaFrench factors (RMFR, $S M B$ and $H M L$ ) for each market to use as explanatory variables, and three dummies to capture Optimistic $(O P)$, Pessimistic $(P)$ and Mild Sentiment $(M)$ periods, respectively. Using the Antoniou et al. (2012) approach, in each month t, we calculate the average level of investor sentiment for the previous 3 months, using a weight of $3 / 6$ for month $t$, a weight of $2 / 6$ for month $t-1$ and a weight of $1 / 6$ for month $t-2$. The top $30 \%$ observations of this rolling average time series are the high sentiment periods, and the bottom $30 \%$ are the low sentiment periods. To identify each holding-period month as optimistic or pessimistic, we calculate the number of high (low) sentiment periods in the $\mathrm{K}$ formation periods. If all $\mathrm{K}$ formation periods classify as optimistic (pessimistic) the holdingperiod month is classified as optimistic (pessimistic). Otherwise, the holding period is classified as Mild. As the sentiment indicator, we use the Baker and Wurgler (2006) index, which can be accessed at http://www.stern.nyu.edu/ jwurgler). Note, further, that we use the orthogonalized BW index. This index has been orthogonalized with respect to a set of macroeconomic conditions. The decision to use the BW index instead of an individual index for each of the markets considered was driven by data availability. Further support for this choice appears in Corredor et al. (2013) where this index is shown to have greater capacity to predict the future returns of these European stock markets, mainly because it provides a more complete body of data than is usually available for these markets individually. 
The results are given in Table 10. In all four of the markets analyzed, the return to the $\mathrm{J}=6 \mathrm{y} \mathrm{K}=6$ momentum strategy is higher, on average, in optimistic than in pessimistic periods, although the difference is significant only in France and the UK, partially confirming the findings of Antoniou et al. (2012). It should be noted that, the individual momentum strategies prove significant only in optimistic market periods, except in the case of Germany, where the significance holds for periods of market pessimism.

The analysis of momentum strategies constructed using high- and low-default risk stocks produces little additional information beyond that provided by the strategies on all the stocks ${ }^{14}$. Indeed, the only point worth noting is that in the case of the strategy constructed from low-default risk stocks, none of the differences between optimistic and pessimistic market periods have a significance level above 5\%, which might suggest that the relationship between momentum and default risk could play a relevant role in explaining market sentiment. which might suggest that market sentiment could play a relevant role in explaining the relationship between momentum and default risk. Nevertheless, in line with Chang et al. (2012) or Corredor et al. (2013), the observed crossmarket differences confirm the importance of the roles played by the country effect and stock characteristics in explaining the impact of market sentiment on stock returns.

With respect to stock characteristics, and particularizing for the momentum strategies analyzed herein, the findings appear to suggest that momentum strategy profits have a clear origin that is linked to the characteristics of the stocks that make up the loser portfolio. However, without denying their importance as variables related with momentum, it should be stressed that the momentum strategy is implemented by simultaneously buying winners and selling losers, and therefore the overall return will depend on the return differential between the winner and loser portfolios. Furthermore, although the stock characteristics of the loser portfolio are fairly clear, (small stock, high BTM, high default risk and illiquidity) the winner portfolio is considerably more difficult to characterize, since its stocks are intermediate in terms of size and default risk, but tend to have lower BTM ratios and higher liquidity. Thus, as this study has revealed, the highest momentum is not necessarily found in the subset of stocks with the same characteristics as the stocks of the loser portfolio. It is also necessary to take into account that the potential impact of the evolution of the winner and loser portfolios against their reference point (Muga and Santamaría, 2009) makes it difficult predict the return for a specific period or specific market. Therefore, the return differential of the winner and loser portfolios used to implement the momentum strategy, which constitutes the very essence of the momentum effect, is still not fully explained, despite recent advancements in characterizing them individually.

${ }^{14}$ Dividing the sample by market state, following Cooper et al. (2004), and taking the cumulative past 36-month returns of the equally weighted market index for each country as the variable yields similar results, not shown to save space but available from the authors upon request. 


\section{Conclusions}

Our results, obtained from data on four developed European stock markets, confirm that default risk is not the key variable in explaining the momentum effect. It is not a question of specific return continuation in low credit-rating stocks, as might be suggested by the findings of Avramov et al. (2007), nor is it a consequence of under-reaction to default risk, as might be deduced from Aggarwal and Taffler (2008).

Our results also indicate that momentum is a more complex phenomenon than might be thought based on the above-mentioned findings. In fact, although the stocks that go into the loser portfolio may be associated with information uncertainty (Jiang et al., 2005 or Zhang, 2006), pricing or arbitrage difficulties (Baker and Wurgler, 2006) or limited attention from investors (Abody et al., 2010), the characteristics of the winner portfolio are less clear-cut, at least with respect to stock size and default risk. Given that the result of implementing a momentum strategy depends on the return differential between the winner and loser portfolios there is no guarantee that the strategies expected to yield the highest returns (small size, high default-risk, etc.) will actually do so. The main reasons for this could be behavioral issues, such as stock market cycle factors (Cooper et al. 2004), investor sentiment (Antoniou et al., 2012), or the evolution of the winner and loser portfolios against their reference point (Muga and Santamaría, 2009), which could be conditioning the whole strategy.

In light of all of the above, and despite having obtained a wider and deeper understanding of the variables related to the momentum effect, the explanation of its origin remains to be clarified. 


\section{Appendix I}

Based on Merton (1974), this study assumes that the value of a firm's assets follows a geometric Brownian motion, given by this expression:

$$
d V_{A}=\mu V_{A} d t+\sigma_{A} V_{A} d W
$$

where $V_{A}$ is the value of the firm's assets, $\mu$ is the expected immediate rate of return on $V_{A}, \sigma_{A}$ is assets-return volatility and $W$ is a standard Brownian motion.

Supposing that the firm is financed entirely by equity and a zero-coupon bond with face book value $D_{t}$ at time $t$ and maturity $T$, default risk can be defined as the probability of the value of the firm's assets at $T$ being less than the book value of its debt, that is:

$$
P_{d e f, t}=\operatorname{Prob}\left(V_{A, T} \leq D_{t} \mid V_{A, t}\right)=\operatorname{Prob}\left(\ln V_{A, T} \leq \ln D_{t} \mid V_{A, t}\right)
$$

Given that firm value follows (1), it can be deduced that:

$$
\ln V_{A, T}=\ln V_{A, t}+\left(\mu_{t}-\frac{\sigma_{A, t}^{2}}{2}\right)(T-t)+\sigma_{A, t} \sqrt{T-t} \varepsilon_{T}
$$

with:

$$
\varepsilon_{T}=\frac{W(T)-W(t)}{\sqrt{T-t}}
$$

where $\varepsilon_{T}$ are iid variables over the interval $\mathrm{N}(0,1)$. Thus, expression (2) can be written as:

$$
\begin{aligned}
& P_{d e f, t}=\operatorname{Prob}\left(\ln V_{A, t}-\ln D_{t}+\left(\mu_{t}-\frac{\sigma_{A, t}^{2}}{2}\right)(T-t)+\sigma_{A, t} \sqrt{T-t} \varepsilon_{T} \leq 0\right) \\
& =\operatorname{Prob}\left(-\frac{\ln \frac{V_{A, t}}{D_{t}}+\left(\mu_{t}-\frac{\sigma_{A, t}^{2}}{2}\right)(T-t)}{\sigma_{A, t} \sqrt{T-t}} \geq \varepsilon_{T}\right)
\end{aligned}
$$


Using the Merton (1974) implied probability distribution, as in other studies in the literature ${ }^{15}$, default risk is given by:

$$
P_{d e f, t}=N\left(-\frac{\ln \frac{V_{A, t}}{D_{t}}+\left(\mu_{t}-\frac{\sigma_{A, t}^{2}}{2}\right)(T-t)}{\sigma_{A, t} \sqrt{T-t}}\right)
$$

where $N(\cdot)$ is the cumulative probability of the Normal distribution.

It is worth noting that in order to implement expression (6), one has to know the value of the firm's assets, $V_{A, t}$, the volatility of its return, $\sigma_{A, t}$, and the value of $\mu_{t}$. However, the value of the firm's assets is not directly observable and therefore neither are the volatility nor the average rate of return. The one observable variable is the market value of equity, $V_{E, t}$ which can be used to estimate the volatility of its return, $\sigma_{E, t}$. Note that Merton (1974), applying Black and Scholes (1973) to the pricing of the firm's equity, find that the value of $V_{E, t}$ is given by the following expression:

$$
V_{E, t}=V_{A, t} N\left(d_{1}\right)-D_{t} e^{-r(T-t)} N\left(d_{2}\right)
$$

with:

$$
\begin{aligned}
& d_{1}=\frac{\ln \frac{V_{A, t}}{D_{t}}+\left(r+\frac{\sigma_{A}^{2}}{2}\right)(T-t)}{\sigma_{A} \sqrt{T-t}} \\
& d_{2}=d_{1}-\sigma_{A} \sqrt{T-t}
\end{aligned}
$$

where $r$ is the risk-free interest rate. Furthermore, it is known that $\sigma_{A, t}$ and $\sigma_{E, t}$ can be related as follows:

$$
\sigma_{E, t}=\frac{V_{A, t}}{V_{E, t}} N\left(d_{1}\right) \sigma_{A, t}
$$

Therefore, by starting from the market price of the firm's equity and solving the system of equations (7) - (10) it is possible to estimate $V_{A, t}, \sigma_{A}$ and $\mu$ and substitute their values in (6) to obtain $P_{d e f, t}$.

15 See Vassalou and Xing (2004), Hillegeist et al. (2004), Byström et al. (2005) and Byström (2006) among others. Instead of using the normal distribution, Moody's KMV uses an empirical distribution of actual defaults based on KMV's large, proprietary database. 
To implement this measure, this study follows a procedure similar to that used by Vassalou and Xing (2004), which begins by estimating the volatility of equity, $\sigma_{E, t}$, by calculating the standard deviation of the last 12 months' return on equity. This estimate of $\sigma_{E, t}$ is taken as the initial value for the estimation of $\sigma_{A, t}$. Substitution of $\sigma_{A, t}, \sigma_{E, t}$ and $V_{E, t}$ into the system of equations (7) - (10) gives the initial value of $V_{A, t}$. The described process is then repeated for every month of the study period to obtain a series of $V_{A, t}$ estimates. To estimate $\sigma_{A, t}$, instead of applying expression (10) directly, a more complex iterative procedure is used. Thus, starting from the values estimated for $V_{A, t}$, it is obtained the first estimation identified as the standard deviation of its return over the previous 12 months. The process is then repeated until the values of $\sigma_{A, t}$ converge for two consecutive iterations, for a tolerance level of 0.001. Having found the convergence value of $\sigma_{A, t}$, the final value of $V_{A, t}$ can be obtained using expression (7). By calculating the average annual variation in $\ln V_{A, t}$ over the previous 12 months, we can obtain an estimate of the value of $\mu_{t}$. In the event that the estimated value of $\mu_{t}$ is lower than the annual risk-free interest rate for that month, $r_{t}$, as in Hillegeist et al. (2004), it is understood that $\mu_{t}=r_{t}$. Finally, expression (6) is used to derive the value of $P_{d e f, t}$. 


\section{References}

Abody D., R. Lehavy, and B. Trueman, 2010, Limited attention and the earnings announcement returns of past stock market winners, Review of Accounting Studies 15, 317-344.

Agarwal, V. and R. Taffler, 2008, Does financial distress risk drive the momentum anomaly?, Financial Management 37, 461-484.

Altman, E. I., 1968, Financial ratios, discriminant analysis and the prediction of corporate bankruptcy, Journal of Finance 23, 589-609.

Amihud, Y., 2002, Illiquidity and stock returns: cross-section and time-series effects, Journal of Financial Markets 5, 31-56.

Antoniou C., J.A. Doukas, and A. Subrahmanyam, 2012, Cognitive Dissonance, Sentiment, and Momentum, Journal of Financial and Quantitative Analysis. Forthcoming.

Avramov, D., T. Chordia, G. Jostova, and A. Philipov, 2007, Momentum and credit rating, Journal of Finance 62, 2503-2520.

Baker, M., and J. Wurgler, 2006, Investor sentiment and the cross-section of stock returns, Journal of Finance 61, 1645-1680.

Black, F., and M. Scholes, 1973, The pricing of options and corporate liabilities, Journal of Political Economy 81, 637-654.

Byström, H., 2006, Merton unraveled: A flexible way of modeling default risk, Journal of Alternative Investments 8, 39-47.

Byström, H., L. Worasinchai, and S. Chongsithipol, 2005, Default risk, systematic risk and Thai firms before, during and after the Asian crisis, Research in International Business and Finance 19, 95-110.

Chang, Y.Y., R. Faff, and C.Y. Hwang, 2012, Local and global sentiment effects, and the role of legal, information and trading. Available at: http://ssrn.com/abstract=1800550 or http://dx.doi.org/10.2139/ssrn.1800550.

Cooper, M.J., R.C. Gutierrez, and A. Hameed, 2004, Market states and momentum, Journal of Finance 59, 1345-1365.

Corredor, P., E. Ferrer, and R. Santamaria, 2013, Investor sentiment effect in stock markets: stock characteristics or country-specific factors, International Review of Economics and Finance, Forthcoming.

Crosbie, P., and J. Bohn, 2003, Modeling default risk. Moody's KMV.

Crouhy, M., D. Galai, and R. Mark, 2000, A comparative analysis of current credit risk models, Journal of Banking and Finance 24, 59-117.

Daniel K., and S. Titman, 1997, Evidence on the characteristics of cross sectional variation in stock returns, Journal of Finance 52, 1-33. 
Grinblatt, M., and B. Han, 2005, Prospect Theory, Mental Accounting, and Momentum, Journal of Financial Economics 78, 311-339.

Hameed, A., and Y. Kusnadi, 2002, Momentum strategies: Evidence from pacific basin stock markets, Journal of Financial Research 25, 383-397.

Hillegeist, S.A., E.K. Keating, D.P. Cram, and K.G. Lundstedt, 2004, Assessing the Probability of Bankruptcy, Review of Accounting Studies 9, 5-34.

Hirshleifer, D., 2001, Investor Psychology and Asset Pricing, Journal of Finance 56, 15331597.

Hong, H., T. Lim, and J.C. Stein, 2000, Bad news travel slowly: Size, analyst coverage, and the profitability of momentum strategies, Journal of Finance 55, 265-295.

Ince, O.S., and R.B. Porter, 2006, Individual equity return data from Thomson Datastream: Handle with care!, Journal of Financial Research 29, 463-479.

Jegadeesh, N., and S. Titman, 1993, Returns to buying winners and selling losers: Implications for stock market efficiency, Journal of Finance 48, 65-91.

Jegadeesh, N., and S. Titman, 2001, Profitability of momentum strategies: an evaluation of alternative explanations, Journal of Finance 56, 699-720.

Jiang, G., C. Lee, M.C. Lee, and G.Y. Zhang, 2005, Information uncertainty and expected stock returns, Review of Accounting Studies 10, 185-221.

Kent, D., D. Hirshleifer, and A. Busrahmanyam, 1998, Investor psychology and security market under- and overreactions, Journal of Finance 53, 1839-1885.

Kent, D., D. Hirshleifer, and A. Busrahmanyam, 2001, Overconfidence, Arbitrage, and Equilibrium Asset Pricing, Journal of Finance 56, 921-965.

Kumar, A., 2009, Hard-to-value stocks, behavioral biases, and informed trading, Journal of Financial and Quantitative Analysis 44, 1375-1401.

Merton, R. C., 1974, On the pricing of corporate debt: The risk structure of interest rates, Journal of Finance 29, 449-470.

Muga, L., and R. Santamaría, 2007a, The momentum effect in Latin American Emerging Markets, Emerging Markets Finance and Trade 43, 25-46.

Muga, L., and R. Santamaría 2007b, "New Economy" Firms and Momentum, Journal of Behavioral Finance 8, 109-120.

Muga, L., and R. Santamaría, 2009, Momentum, market states and investor behaviour. Empirical Economics 37, 105-130.

Newey, W.K., and K.D. West, 1987, A simple, positive semi-definite, heteroskedasticity and autocorrelation consistent covariance matrix, Econometrica 55, 703-708.

Ohlson, J., 1980, Financial ratios and the probabilistic prediction of bankruptcy, Journal of Accounting Research 18, 109-131. 
Rouwenhorst, K.G., 1998, International momentum strategies, Journal of Finance 53, 267 284.

Vassalou, M., and Y. Xing, 2004, Default risk in equity returns, Journal of Finance 49, 831868.

Zhang, X.F., 2006, Information uncertainty and stock returns, Journal of Finance 61, 105136. 
Table 1: Descriptive statistics of the sample

This table shows the average values of the stock characteristic variables used in the analysis: Valueweighted Return, Size (LN of market capitalization), BTM and Default risk (BSM), and the average, maximum and minimum number of stocks.

\begin{tabular}{lccccccc}
\hline & Return & Size & BTM & BSM & Avg. & Min. & Max. \\
\hline France & 0.0101 & 18.14 & 0.77795 & 0.01417 & 393 & 190 & 478 \\
Germany & 0.0077 & 18.50 & 0.75293 & 0.02458 & 226 & 40 & 430 \\
Spain & 0.0131 & 19.77 & 0.68409 & 0.00837 & 88 & 61 & 105 \\
United Kingdom & 0.0101 & 17.55 & 0.63362 & 0.00751 & 485 & 152 & 925 \\
\hline
\end{tabular}


Table 2: Momentum Returns

This table presents the monthly returns for the 4 momentum strategies, and for the winner and loser portfolios on which they are based for the period January1993 January 2007. Calendar-time returns are given for the 4 stock markets considered (France, Germany, Spain and the United Kingdom) and the full sample of stocks from all four markets for a formation period of $\mathrm{J}=6$ and holding periods of $\mathrm{K}=3,6,9,12 .{ }^{*}$ and \# denote returns that are significant at the $5 \%$ and $10 \%$ levels, respectively, using the Newey-West (1987) standard errors.

\begin{tabular}{|c|c|c|c|c|c|c|c|c|}
\hline FRANCE & MOM63 & & MOM66 & & MOM69 & & MOM612 & \\
\hline Loser & -0.002193 & & -0.002746 & & -0.003038 & & -0.002734 & \\
\hline Winner & 0.010526 & * & 0.010167 & $*$ & 0.009655 & $*$ & 0.008739 & \# \\
\hline Momentum & 0.012719 & * & 0.012912 & * & 0.012693 & $*$ & 0.011473 & * \\
\hline GERMANY & MOM63 & & MOM66 & & MOM69 & & MOM612 & \\
\hline Loser & -0.013591 & & -0.013491 & & -0.013925 & \# & -0.013770 & \\
\hline Winner & 0.007032 & & 0.005584 & & 0.005014 & & 0.004096 & \\
\hline Momentum & 0.020622 & * & 0.019075 & * & 0.018940 & $*$ & 0.017865 & * \\
\hline SPAIN & MOM63 & & MOM66 & & MOM69 & & MOM612 & \\
\hline Loser & 0.010957 & * & 0.011193 & * & 0.011484 & $*$ & 0.012029 & * \\
\hline Winner & 0.018030 & * & 0.017063 & * & 0.016912 & $*$ & 0.016259 & * \\
\hline Momentum & 0.007073 & * & 0.005870 & * & 0.005428 & $*$ & 0.004230 & * \\
\hline$U K$ & MOM63 & & MOM66 & & MOM69 & & MOM612 & \\
\hline Loser & -0.015292 & * & -0.013501 & * & -0.012156 & \# & -0.010438 & \\
\hline Winner & 0.011167 & * & 0.009401 & \# & 0.008190 & & 0.006465 & \\
\hline Momentum & 0.026459 & * & 0.022903 & * & 0.020356 & $*$ & 0.016903 & * \\
\hline FULL SAMPLE & MOM63 & & MOM66 & & MOM69 & & MOM612 & \\
\hline Loser & -0.010155 & \# & -0.009443 & \# & -0.008772 & \# & -0.007637 & \\
\hline Winner & 0.011128 & * & 0.009648 & $*$ & 0.008711 & $*$ & 0.007401 & * \\
\hline Momentum & 0.021283 & * & 0.019092 & $*$ & 0.017483 & $*$ & 0.015038 & * \\
\hline
\end{tabular}


Table 3: Characteristics of Momentum Portfolios

This table presents the default risk (BSM score), Size (LN of market capitalization) and BTM characteristics of the portfolios for the $\mathrm{J}=6$ formation period in each of the markets considered and the full sample of stocks from all four markets for the period January1993January 2007.

\begin{tabular}{lccccc}
\hline $\boldsymbol{F R A N C E}$ & Loser & $\mathbf{2}$ & $\mathbf{3}$ & $\mathbf{4}$ & Winner \\
\hline BSM & 0.0273 & 0.0121 & 0.0094 & 0.0102 & 0.0097 \\
SIZE & 17.55 & 18.05 & 18.28 & 18.40 & 18.38 \\
BTM & 0.9365 & 0.8713 & 0.8153 & 0.7551 & 0.6377 \\
\hline $\boldsymbol{G E R M A N Y}$ & Loser & $\mathbf{2}$ & $\mathbf{3}$ & $\mathbf{4}$ & Winner \\
\hline BSM & 0.0382 & 0.0196 & 0.0126 & 0.0110 & 0.0094 \\
SIZE & 18.13 & 18.85 & 19.33 & 19.49 & 19.19 \\
BTM & 0.7712 & 0.6924 & 0.6523 & 0.6141 & 0.5105 \\
\hline SPAIN & Loser & $\mathbf{2}$ & $\mathbf{3}$ & $\mathbf{4}$ & Winner \\
\hline BSM & 0.0155 & 0.0056 & 0.0043 & 0.0049 & 0.0074 \\
SIZE & 19.35 & 19.72 & 19.97 & 20.02 & 19.74 \\
BTM & 0.7706 & 0.7672 & 0.7115 & 0.6817 & 0.5954 \\
\hline $\boldsymbol{U K}$ & Loser & $\mathbf{2}$ & $\mathbf{3}$ & $\mathbf{4}$ & Winner \\
\hline BSM & 0.0173 & 0.0064 & 0.0043 & 0.0032 & 0.0047 \\
SIZE & 16.81 & 17.54 & 17.91 & 18.04 & 17.79 \\
BTM & 0.7623 & 0.6551 & 0.6078 & 0.5574 & 0.4758 \\
\hline $\boldsymbol{F U L L ~} \boldsymbol{S A M P L E}$ & Loser & $\mathbf{2}$ & $\mathbf{3}$ & $\mathbf{4}$ & Winner \\
\hline BSM & 0.0262 & 0.0114 & 0.0079 & 0.0070 & 0.0081 \\
SIZE & 17.51 & 18.24 & 18.56 & 18.69 & 18.42 \\
BTM & 0.8451 & 0.7662 & 0.7206 & 0.6561 & 0.5520 \\
\hline & & & & & \\
\hline
\end{tabular}


Table 4: Momentum and credit rating

This table presents the monthly momentum strategy, returns for the $\mathrm{J}=6$ $\mathrm{K}=6$ winner and loser portfolios for the period January1993 - January 2007 for the stock markets considered (France, Germany, Spain and the United Kingdom) and the full sample of stocks from all four markets measured in calendar time using the complete FACSET database and data on creditrated firms, and high and low rated firms. * and \# denote returns that are significant at the $5 \%$ and $10 \%$ levels, respectively, using the Newey-West (1987) standard errors.

\begin{tabular}{|c|c|c|c|c|c|}
\hline FRANCE & Loser & & Winner & & Momentum \\
\hline FACSET & -0.00125 & & 0.00788 & & 0.00913 \\
\hline Rated firms & 0.00547 & & 0.00980 & \# & 0.00433 \\
\hline High Rating & 0.00836 & & 0.00898 & & 0.00062 \\
\hline Low Rating & 0.00239 & & 0.00770 & & 0.00531 \\
\hline GERMANY & Loser & & Winner & & Momentum \\
\hline FACSET & -0.01696 & $*$ & 0.00113 & & $0.01810 *$ \\
\hline Rated firms & 0.00887 & & 0.00850 & & -0.00036 \\
\hline High Rating & 0.00778 & & 0.00884 & & 0.00105 \\
\hline Low Rating & 0.01184 & & 0.00418 & & -0.00489 \\
\hline SPAIN & Loser & & Winner & & Momentum \\
\hline FACSET & 0.00887 & & 0.01948 & $*$ & $0.01061 *$ \\
\hline Rated firms & 0.01382 & & 0.01150 & & -0.00231 \\
\hline High Rating & 0.01418 & & 0.01103 & & -0.00315 \\
\hline Low Rating & 0.01364 & & 0.01241 & & -0.00123 \\
\hline$U K$ & Loser & & Winner & & Momentum \\
\hline FACSET & 0.00217 & & 0.01415 & $*$ & $0.01198 *$ \\
\hline Rated firms & 0.00679 & & 0.01255 & $*$ & 0.00576 \\
\hline High Rating & 0.00772 & & 0.00917 & & 0.00146 \\
\hline Low Rating & 0.00709 & & 0.01419 & * & 0.00710 \\
\hline FULL SAMPLE & Loser & & Winner & & Momentum \\
\hline FACSET & -0.00730 & & 0.00861 & * & $0.01591 *$ \\
\hline Rated firms & 0.00795 & $\#$ & 0.01070 & * & 0.00275 \\
\hline High Rating & 0.00892 & $*$ & 0.00888 & * & -0.00004 \\
\hline Low Rating & 0.00680 & & 0.01063 & * & 0.00383 \\
\hline
\end{tabular}




\section{Table 5: Momentum by default risk groups}

This table presents the monthly momentum strategy returns of the $\mathrm{J}=6$; $\mathrm{K}=6$ winner and loser portfolios for the period January 1993 - January 2007 by high, medium and low BSM default risk levels sorted into quartiles for the full sample of stocks, UK, German and French markets and into tertiles for the Spanish market. * and \# denote returns that are significant at the $5 \%$ and $10 \%$ levels, respectively, using the Newey-West (1987) standard errors.

\begin{tabular}{|c|c|c|c|c|c|c|}
\hline$F R A N C E$ & Loser & & Winner & & Momentum & \\
\hline LOW BSM & 0.000058 & & 0.012533 & $*$ & 0.012475 & * \\
\hline 2 & -0.001441 & & 0.009632 & $\#$ & 0.011073 & * \\
\hline 3 & -0.005722 & & 0.009718 & $\#$ & 0.015440 & $*$ \\
\hline HIGH BSM & -0.002294 & & 0.006837 & & 0.009131 & $\#$ \\
\hline GERMANY & Loser & & Winner & & Momentum & \\
\hline LOW BSM & -0.011108 & & 0.011251 & $\#$ & 0.022360 & $*$ \\
\hline 2 & -0.011515 & & 0.002872 & & 0.014387 & * \\
\hline 3 & -0.015761 & \# & 0.004407 & & 0.020167 & $*$ \\
\hline HIGH BSM & -0.012388 & & 0.001713 & & 0.014101 & $*$ \\
\hline SPAIN & Loser & & Winner & & Momentum & \\
\hline LOW BSM & 0.008620 & $*$ & 0.011867 & $*$ & 0.003247 & \\
\hline 2 & 0.011818 & * & 0.013954 & $*$ & 0.002136 & \\
\hline HIGH BSM & 0.012644 & \# & 0.019968 & $*$ & 0.007324 & * \\
\hline$U K$ & Loser & & Winner & & Momentum & \\
\hline LOW BSM & -0.011602 & $*$ & 0.006385 & & 0.017988 & $*$ \\
\hline 2 & -0.011172 & * & 0.010467 & $*$ & 0.021639 & $*$ \\
\hline 3 & -0.015584 & * & 0.011925 & $*$ & 0.027509 & * \\
\hline HIGH BSM & -0.013093 & * & 0.006467 & & 0.019560 & * \\
\hline FULL SAMPLE & Loser & & Winner & & Momentum & \\
\hline LOW BSM & -0.008548 & \# & 0.009471 & $*$ & 0.018018 & $*$ \\
\hline 2 & -0.009064 & \# & 0.010359 & $*$ & 0.019423 & * \\
\hline 3 & -0.010712 & * & 0.010465 & $*$ & 0.021176 & * \\
\hline HIGH BSM & -0.009686 & & 0.006722 & $\#$ & 0.016408 & * \\
\hline
\end{tabular}


Table 6: Independent sort by default risk and alternative firm characteristics

This table presents the January 1993-January 2007, J=6 K=6, momentum strategy returns from the independent sort by BSM default risk levels and stock characteristics (Size and BTM), sorted into tertiles for all samples except Spain, for which the median is used to categorize the stocks as high or low with respect to the variables in question. * and \# denote returns that are significant at the 5\% and 10\% levels, respectively, using the Newey-West (1987) standard errors.

\begin{tabular}{|c|c|c|c|c|c|c|c|c|c|c|c|c|c|}
\hline \multirow{2}{*}{\multicolumn{2}{|c|}{ FRANCE }} & \multicolumn{6}{|c|}{ SIZE } & \multicolumn{6}{|c|}{ BTM } \\
\hline & & LOW & & 2 & & HIGH & & LOW & & 2 & & HIGH & \\
\hline & LOW & 0.001096 & & 0.013811 & & 0.009435 & $*$ & 0.014794 & $*$ & 0.007392 & $*$ & 0.003004 & \\
\hline BSM & HIGH & 0.001557 & & 0.014661 & * & 0.013075 & $*$ & 0.023869 & $*$ & 0.013678 & $*$ & 0.001855 & \\
\hline GERMANY & & \multicolumn{6}{|c|}{ SIZE } & \multicolumn{6}{|c|}{ BTM } \\
\hline \multirow[t]{2}{*}{ BSM } & 2 & 0.008554 & & 0.022784 & * & 0.013705 & $*$ & 0.021606 & $*$ & 0.021414 & $*$ & 0.007518 & \# \\
\hline & HIGH & 0.008467 & & 0.023282 & * & 0.012367 & \# & 0.016807 & $*$ & 0.015991 & $*$ & 0.010133 & \# \\
\hline \multirow{2}{*}{\multicolumn{2}{|c|}{ SPAIN }} & & & \multicolumn{4}{|c|}{ SIZE } & \multicolumn{4}{|c|}{ BTM } & & \\
\hline & & & & LOW & & HIGH & & LOW & & HIGH & & & \\
\hline \multirow{2}{*}{$U K$} & & LOW & & 2 & & HIGH & & LOW & & 2 & & HIGH & \\
\hline & LOW & 0.015649 & * & 0.020167 & * & 0.019126 & $*$ & 0.025451 & $*$ & 0.018763 & $*$ & 0.013068 & * \\
\hline \multirow[t]{2}{*}{ BSM } & 2 & 0.022910 & * & 0.029785 & * & 0.019787 & $*$ & 0.037767 & $*$ & 0.029036 & $*$ & 0.009276 & * \\
\hline & HIGH & 0.020619 & * & 0.027684 & * & 0.018176 & $*$ & 0.033175 & $*$ & 0.023832 & $*$ & 0.017139 & * \\
\hline \multirow{2}{*}{\multicolumn{2}{|c|}{ FULL SAMPLE }} & \multicolumn{6}{|c|}{ SIZE } & \multicolumn{6}{|c|}{ BTM } \\
\hline & & LOW & & 2 & & HIGH & & LOW & & 2 & & HIGH & \\
\hline & LOW & 0.015888 & * & 0.024572 & * & 0.015391 & * & 0.024972 & $*$ & 0.018664 & $*$ & 0.009731 & * \\
\hline \multirow[t]{2}{*}{ BSM } & 2 & 0.021486 & * & 0.022392 & * & 0.015628 & * & 0.030544 & $*$ & 0.020112 & $*$ & 0.011060 & * \\
\hline & HIGH & 0.014014 & * & 0.024792 & * & 0.013807 & * & 0.027701 & $*$ & 0.025282 & $*$ & 0.011102 & * \\
\hline
\end{tabular}


Table 7: Default risk-neutral momentum strategies

This table presents the January 1993-January 2007, J=6 K=6 default risk-neutral momentum strategy returns of the winner and loser portfolios, and the results of these strategies conditioned on Size (by market capitalization) and BTM for the four markets considered and the full sample of stocks from all four markets. * and \# denote returns that are significant at the $5 \%$ and $10 \%$ levels, respectively, using the Newey-West (1987) standard errors.

\begin{tabular}{|c|c|c|c|}
\hline FRANCE & Default Risk Neutral & $\begin{array}{l}\text { Default Risk Neutral } \\
\text { moderated by size }\end{array}$ & $\begin{array}{l}\text { Default Risk Neutral } \\
\text { moderated by BTM }\end{array}$ \\
\hline Loser & -0.0024 & -0.0011 & -0.0022 \\
\hline Winner & $0.0096 *$ & $0.0086 \#$ & $0.0088 *$ \\
\hline Momentum & $0.0120 *$ & $0.0097 *$ & $0.0110 *$ \\
\hline GERMANY & Default Risk Neutral & $\begin{array}{l}\text { Default Risk Neutral } \\
\text { moderated by size }\end{array}$ & $\begin{array}{l}\text { Default Risk Neutral } \\
\text { moderated by BTM }\end{array}$ \\
\hline Loser & -0.0127 & -0.0114 & -0.0120 \\
\hline Winner & 0.0051 & 0.0034 & 0.0038 \\
\hline Momentum & $0.0178 *$ & $0.0148 *$ & $0.0158 *$ \\
\hline SPAIN & Default Risk Neutral & $\begin{array}{l}\text { Default Risk Neutral } \\
\text { moderated by size }\end{array}$ & $\begin{array}{l}\text { Default Risk Neutral } \\
\text { moderated by BTM }\end{array}$ \\
\hline Loser & $0.0110 *$ & $0.0105 *$ & $0.0104 *$ \\
\hline Winner & $0.0152 *$ & $0.0155 *$ & $0.0156 *$ \\
\hline Momentum & $0.0042 *$ & $0.0050 *$ & $0.0052 *$ \\
\hline$U K$ & Default Risk Neutral & $\begin{array}{l}\text { Default Risk Neutral } \\
\text { moderated by size }\end{array}$ & $\begin{array}{l}\text { Default Risk Neutral } \\
\text { moderated by BTM }\end{array}$ \\
\hline Loser & $-0.0129 *$ & $0.0130 \#$ & $-0.0131 *$ \\
\hline Winner & $0.0088 \#$ & $0.0085 \#$ & $0.0099 *$ \\
\hline Momentum & $0.0217 *$ & $0.0215 *$ & $0.0230 *$ \\
\hline FULL SAMPLE & Default Risk Neutral & $\begin{array}{l}\text { Default Risk Neutral } \\
\text { moderated by size }\end{array}$ & $\begin{array}{c}\text { Default Risk Neutral } \\
\text { moderated by BTM }\end{array}$ \\
\hline Loser & $-0.0095 \#$ & $-0.0095 \#$ & $-0.0100 *$ \\
\hline Winner & $0.0093 *$ & $0.0089 *$ & $0.0099 *$ \\
\hline Momentum & $0.0188 *$ & $0.0183 *$ & $0.0199 *$ \\
\hline
\end{tabular}




\section{Table 8: Liquidity and momentum portfolios}

This table describes the $\mathrm{J}=6$ portfolio liquidity, proxied by Amihud's (2002) ratio, in the four stock markets considered and the full sample of stocks from all four markets, for the period January 1999 -January 2007.

\begin{tabular}{lccccc}
\hline & Loser & $\mathbf{2}$ & $\mathbf{3}$ & $\mathbf{4}$ & Winner \\
\hline FRANCE & 8.747 & 4.435 & 3.345 & 2.846 & 3.715 \\
GERMANY & 14.654 & 12.521 & 8.590 & 8.214 & 7.690 \\
SPAIN & 0.444 & 0.433 & 0.315 & 0.252 & 0.206 \\
UK & 0.077 & 0.049 & 0.034 & 0.028 & 0.031 \\
FULL SAMPLE & 2.600 & 0.866 & 0.002 & 1.998 & 1.892 \\
\hline
\end{tabular}


Table 9: Independent sort by credit risk and liquidity

This table presents the January 1999-January 2007, J=6 K=6, momentum strategy returns from the independent sort by BSM credit risk levels and Amihud's (2002) illiquidity ratios, sorted into tertiles for and the full sample of stocks from all four markets and all countries except Spain, for which the median is used to categorize the stocks as high or low with respect to the variables in question. * and \# denote returns that are significant at the $5 \%$ and $10 \%$ levels, respectively, using the Newey-West (1987) standard errors.

\begin{tabular}{|c|c|c|c|c|c|c|}
\hline \multirow[t]{3}{*}{ FRANCE } & & \multicolumn{5}{|c|}{ ILIQUIDITY } \\
\hline & & LOW & & 2 & & HIGH \\
\hline & LOW & 0.01070 & $*$ & 0.01270 & * & 0.00360 \\
\hline \multirow[t]{2}{*}{ BSM } & 2 & 0.01254 & $*$ & 0.01603 & * & $0.01894 *$ \\
\hline & HIGH & 0.01757 & $*$ & 0.02802 & $*$ & 0.00517 \\
\hline \multirow[t]{3}{*}{ GERMANY } & & \multicolumn{5}{|c|}{ ILIQUIDITY } \\
\hline & & LOW & & 2 & & HIGH \\
\hline & LOW & 0.02445 & $*$ & 0.02313 & * & $0.01239 *$ \\
\hline \multirow[t]{2}{*}{ BSM } & 2 & 0.03320 & $*$ & 0.02565 & * & $0.02190 *$ \\
\hline & HIGH & 0.01916 & $*$ & 0.00998 & & 0.00097 \\
\hline \multirow{2}{*}{\multicolumn{2}{|c|}{ SPAIN }} & \multicolumn{4}{|c|}{ ILIQUIDITY } & \\
\hline & & LOW & & HIGH & & \\
\hline \multirow{2}{*}{ BSM } & LOW & 0.00196 & & $0.00842 \neq$ & \# & \\
\hline & HIGH & 0.00342 & $\#$ & 0.00806 & $*$ & \\
\hline \multirow[t]{3}{*}{$U K$} & & \multicolumn{5}{|c|}{ ILIQUIDITY } \\
\hline & & LOW & & 2 & & HIGH \\
\hline & LOW & 0.02207 & $*$ & 0.02181 & * & 0.01162 \\
\hline \multirow[t]{2}{*}{ BSM } & 2 & 0.02359 & $*$ & 0.02342 & $*$ & $0.03361 *$ \\
\hline & HIGH & 0.02389 & $*$ & 0.02986 & $*$ & $0.02812 *$ \\
\hline \multirow{2}{*}{\multicolumn{2}{|c|}{ FULL SAMPLE }} & \multicolumn{5}{|c|}{ ILIQUIDITY } \\
\hline & & LOW & & 2 & & HIGH \\
\hline & LOW & 0.018295 & $*$ & 0.027560 & $*$ & 0.020583 * \\
\hline \multirow[t]{2}{*}{ BSM } & 2 & 0.021790 & $*$ & 0.024529 & $*$ & 0.021630 * \\
\hline & HIGH & 0.023743 & $*$ & 0.034591 & $*$ & $0.015217 *$ \\
\hline
\end{tabular}


Table 10: Momentum, default risk and investor sentiment

This table presents the results of the regression of the time series of momentum strategy (J=6 K=6) for all firms (MOM66), for high default risk firms (MOM66HDR) and for low default risk (MOM66LDR) on Fama-French factors ( $R M R F$, $S M B$ and $H M L)$ and three dummy variables: Optimistic $(O P)$, mild $(M)$ or pessimistic $(P)$ period computed following the procedure by Antoniou et al. (2012). We use the orthogonalized Baker and Wurgler's (2006) investor sentiment index. The period is January 1999-January 2007. The t-statistics of the significance of momentum profits and the difference between profits derived after optimistic and pessimistic periods are calculated using Newey-West standard errors.

\begin{tabular}{|c|c|c|c|c|c|c|c|c|c|}
\hline & & RMRF_SEL & SMB & HML & $\mathbf{O P}$ & M & $\mathbf{P}$ & \multicolumn{2}{|c|}{$\mathrm{H}_{0}: \mathrm{OP}=\mathbf{P}$} \\
\hline \multicolumn{10}{|c|}{ Panel A: All the firms } \\
\hline \multirow{2}{*}{ FRANCE } & Coefficient & -0.218349 & 0.065891 & -0.372831 & 0.030381 & 0.013134 & 0.007674 & Chi(1) & 4.775 .239 \\
\hline & $p$-value & 0.1221 & 0.5596 & 0.0424 & 0.0003 & 0.0009 & 0.2834 & p-value & 0.0289 \\
\hline \multirow{2}{*}{ GERMANY } & Coefficient & -0.360614 & -0.519595 & -0.111046 & 0.032266 & 0.021632 & 0.019785 & Chi(1) & 1.129 .345 \\
\hline & $p$-value & 0.0001 & 0.0015 & 0.5914 & 0.0005 & 0.0001 & 0.0022 & $\mathrm{p}$-value & 0.2879 \\
\hline \multirow{2}{*}{ SPAIN } & Coefficient & -0.187201 & -0.213099 & -0.019706 & 0.006205 & 0.012334 & -0.004406 & Chi(1) & 0.952564 \\
\hline & $p$-value & 0.0477 & 0.0745 & 0.9052 & 0.2887 & 0.0007 & 0.6333 & p-value & 0.3291 \\
\hline \multirow{2}{*}{ UK } & Coefficient & -0.301614 & -0.028103 & -0.274891 & 0.033439 & 0.024943 & 0.007708 & $\operatorname{Chi}(1)$ & 5.146 .799 \\
\hline & $p$-value & 0.0495 & 0.8861 & 0.0645 & 0.0011 & 0 & 0.4377 & $\mathrm{p}$-value & 0.0233 \\
\hline \multicolumn{10}{|c|}{ Panel B: High default risk firms } \\
\hline \multirow{2}{*}{ FRANCE } & Coefficient & -0.404939 & -0.18139 & -0.269348 & 0.037394 & 0.007684 & 0.003368 & Chi(1) & 6.250 .237 \\
\hline & $p$-value & 0.0534 & 0.2423 & 0.3606 & 0.0006 & 0.1638 & 0.7451 & $\mathrm{p}$-value & 0.0124 \\
\hline \multirow{2}{*}{ GERMANY } & Coefficient & -0.40104 & -0.512688 & -0.125515 & 0.025313 & 0.017868 & 0.015146 & Chi(1) & 0.396298 \\
\hline & $p$-value & 0.0005 & 0.0192 & 0.5286 & 0.0321 & 0.0139 & 0.0787 & $p$-value & 0.529 \\
\hline \multirow{2}{*}{ SPAIN } & Coefficient & -0.242271 & -0.241669 & 0.005973 & 0.006686 & 0.014202 & -0.001611 & Chi(1) & 0.354676 \\
\hline & $p$-value & 0.0039 & 0.1323 & 0.9704 & 0.3442 & 0.0011 & 0.9013 & $\mathrm{p}$-value & 0.5515 \\
\hline \multirow{2}{*}{ UK } & Coefficient & -0.435984 & -0.130394 & -0.050478 & 0.0217 & 0.024287 & 0.007948 & Chi(1) & 11.528 \\
\hline & $p$-value & 0.0107 & 0.45 & 0.7944 & 0.0566 & 0 & 0.3472 & $\mathrm{p}$-value & 0.283 \\
\hline \multicolumn{10}{|c|}{ Panel C: Low default risk firms } \\
\hline \multirow{2}{*}{ FRANCE } & Coefficient & -0.038428 & 0.250747 & -0.472819 & 0.017347 & 0.01427 & 0.013628 & Chi(1) & 0.133345 \\
\hline & $p$-value & 0.6583 & 0.0186 & 0.0003 & 0.0354 & 0.0001 & 0.0582 & $\mathrm{p}$-value & 0.715 \\
\hline \multirow{2}{*}{ GERMANY } & Coefficient & -0.254232 & -0.347335 & -0.180422 & 0.035039 & 0.022495 & 0.028554 & Chi(1) & 0.170966 \\
\hline & $p$-value & 0.0737 & 0.0411 & 0.4661 & 0.002 & 0.0014 & 0.0063 & $\mathrm{p}$-value & 0.6793 \\
\hline \multirow{2}{*}{ SPAIN } & Coefficient & 0.046205 & 0.00185 & 0.0688 & 0.003717 & 0.007173 & -0.003384 & Chi(1) & 0.354654 \\
\hline & $p$-value & 0.5404 & 0.9841 & 0.6545 & 0.5634 & 0.0189 & 0.5801 & $\mathrm{p}$-value & 0.5515 \\
\hline \multirow{2}{*}{ UK } & Coefficient & -0.275838 & 0.065838 & -0.278512 & 0.03521 & 0.013507 & 0.010616 & Chi(1) & 2.830 .636 \\
\hline & $p$-value & 0.1265 & 0.775 & 0.0989 & 0.0004 & 0.0128 & 0.4337 & p-value & 0.0925 \\
\hline
\end{tabular}

